\title{
Biometric and biochemical attributes of alfalfa seedlings as indicators of stress induced by excessive cadmium
}

\author{
S. Mahmood ${ }^{1,2}$, S. A. Malik ${ }^{2}$, A. Tabassum ${ }^{2}$, U. Younis ${ }^{2}$ and M. Athar ${ }^{3,4^{*}}$ \\ ${ }^{1}$ Division of Experimental and Evolutionary Biology, University of Glasgow, Glasgow, Scotland, G12 8QQ, UK. ${ }^{2}$ Institute of \\ Pure and Applied Biology, Botany Division, Bahauddin Zakariya University, Multan-60800, Pakistan. ${ }^{3}$ California Department \\ of Food and Agriculture, 3288 Meadowview Road, Sacramento, CA 95832, USA. ${ }^{4}$ Department of Food Science and Technology, \\ University of Karachi, Karachi-75270, Pakistan.*Corresponding author: atariq@cdfa.ca.gov
}

\begin{abstract}
The biometric and biochemical attributes of alfalfa (Medicago sativa L.) seedlings were studied after their exposure to $0-120 \mu \mathrm{M}$ cadmium for 28 days using hydroponic culture. The growth, photosynthetic area and pigment contents (chlorophyll a, $\mathrm{b}$ and total) declined significantly $(p \leq 0.05)$ in the presence of high cadmium concentrations $(90$ and $120 \mu \mathrm{M})$. A steady increase in lipid peroxidation assessed via MDA production was observed with increasing levels of cadmium. Cadmium uptake by the plant tissues was concentration dependent. The roots accumulated $1020 \mu \mathrm{g} \mathrm{g}-1$ of cadmium which was two folds than leaves. An enhanced production up to $600 \mu \mathrm{g} \mathrm{g}^{-1}$ of proline was observed at higher levels of cadmium. Though, cadmium toxicity was expressed in terms of decline in growth variables, chlorophyll content and oxidative damage but restricted transfer of the metal to the aerial tissue and greater production of proline in response to higher metal content seems to alleviate cadmium toxicity. Thus, ability of alfalfa plants to tolerate high cadmium concentrations can be a manifestation of effective defensive mechanism derived from differential accumulation of metal in plant tissues in addition to enhanced production of proline.
\end{abstract}

Keywords: Alfalfa, cadmium toxicity, biomass, chlorophyll, malondialdehyde, proline

\section{Introduction}

The hyper-accumulation and toxicity of heavy metals is now a worldwide problem leading to agriculture losses and hazardous health effects as metals enter the food chain (Chmielowska-Bak et al. 2013; Sigel et al. 2013). Among heavy metals, cadmium (Cd)is a toxic pollutant which enters the environment from many industrial processes; electroplating, production of nickel-cadmium batteries, plastic, pigments, ceramics and cement manufacturing (Nriagu, 1996). Since it is a non biodegradable element thus persists indefinitely in the environment. Variations have been reported for the average cadmium content found in soil and water but the sites near urban and industrialized areas have rather high concentrations of this metal (Vasslive, 2002).

Although, complete mechanism of cadmium toxicity is not fully explicit but several studies had demonstrated that it is strongly phytotoxic (Andresen and Kupper, 2013; Garg and Bhandari, 2013; Parmer et al. 2013). Cadmium causes growth inhibition, metabolic and physiological disorders (Elobeid et al. 
2012; Markert et al. 2003). Similarly, photosynthesis is sensitive to cadmium, chlorophyll molecules being one the targets (Lopez-Millan et al. 2009; Parmer et al. 2013; Sandalio et al. 2001). Cadmium can also degrade phospholipids, therefore, alters membrane structure and functions because its ions promote incomplete reduction of molecular oxygen leading to the generation of free radicals due to inhibition of photosynthetic electron transport. Oxidative damage involving lipid peroxidation has been well reported in higher plants in the presence of toxic levels of cadmium (Dhir et al. 2004).

Cadmium is a non-essential micronutrient for plant growth but when it is present in excessive amount it enters the roots and further translocates to the aerial tissues (Reeves and Baker, 2000). Cadmium tolerance varies with different stages of development in plants but higher concentrations of cadmium appeared to be more harmful at seedling stage. Therefore, cadmium tolerance of juvenile plants of different species has intensively been studied (Sharma et al. 2010).

Metal tolerant plants have shown different strategies/ tolerance mechanisms. One of the significant strategies is the differential accumulation of metal in plants tissues. Metal tolerant plants can sequester a large proportion of metals in their roots and allow a restricted transfer to the shoots and foliage (Raskin et al. 1994). Similarly free proline accumulation in plant tissues is positively correlated with heavy metal tolerance as demonstrated by Giannakoula et al. (2008). Increased production of proline permits osmotic adjustment as well as provides protection for enzymes and lipid peroxidation, thus, the integrity of biological membranes is maintained by its production (Basak et al. 2001). Moreover, it is also capable of detoxifying free radicals by forming stable complexes with them, causing a decline in malondialdehyde (MDA); a cytotoxic product of lipid peroxidation which is widely used as an indicative of tissue damage.

Since metal pollution has already rendered agricultural land less productive, therefore identification of species that have enhanced metal tolerance particularly at their establishment phases can be of great significance. Alfalfa (Medicago sativa L.) is an important forage crop, which is widely cultivated in many parts of the world. This crop can be used as a pasture, hay or silage. Moreover, ever increasing demand for protein-rich raw materials for livestock has led to a greater interest in planting forage communities to support small ruminants including sheep and goats in Pakistan (Khan et al. 1999).

Biometric and biochemical traits were used in this study to assess cadmium stress in alfalfa. The changes in growth, chlorophyll, MDA content and bioaccumulation of metal in tissues of alfalfa seedlings were investigated after their exposure to excessive cadmium concentrations. The study also aimed at to reveal the ameliorative role of proline in reducing damaging effects of toxic levels of cadmium.

\section{Materials and Methods}

\subsection{Plant material and cadmium concentration}

The seeds of alfala (Medicago sativa L. var. Sargodha 2002) were obtained from Fodder Research Institute, Sargodha, Pakistan. A seedling cohort was obtained by germinating about 200 seeds in Petridishes $(8 \mathrm{~cm}$ internal diameter) lined with Whatman No. 1 filter paper. Germination was carried out in a growth chamber at $25{ }^{\circ} \mathrm{C}, 12 \mathrm{~h}$ light and dark period, (illumination of 2500 lux, Philips T2 40W/33 lamp). Nutrient solution was prepared by following Hoagland and Arnon (1950). The composition of the basic nutrient solution was ( $\left.\mathrm{mg} \mathrm{L}^{-1}\right)$ : $\left(\mathrm{NH}_{4}\right)_{2} \mathrm{SO}_{4} 48.2$, $\mathrm{MgSO}_{4} 65.9, \mathrm{~K}_{2} \mathrm{SO}_{4} 15.9, \mathrm{KNO}_{3} 18.5, \mathrm{Ca}\left(\mathrm{NO}_{3}\right) 259.9$, $\mathrm{KH}_{2} \mathrm{PO}_{4} 24.8$, Fe-citrate $5, \mathrm{MnCl}_{2} 4 \mathrm{H}_{2} \mathrm{O} 0.9, \mathrm{ZnSO}_{4}$ $7 \mathrm{H}_{2} \mathrm{O} 0.11, \mathrm{CuSO}_{4} 5 \mathrm{H}_{2} \mathrm{O} 0.04, \mathrm{HBO}_{3} 2.9, \mathrm{H}_{2} \mathrm{MoO}_{4}$ 0.1 . The stock solution $(1000 \mu \mathrm{M})$ of cadmium was prepared in Hoagland nutrient solution using $\mathrm{CdCl}_{2}$ (Merck, Germany). The cadmium concentrations $30,60,90,120 \mu \mathrm{M}$ were prepared by diluting 1000 
$\mu \mathrm{M}$ stock with nutrient solution, Hoagland served as control and each treatment was replicated three times.

\subsection{Seedling growth}

This experiment consisted of 18 hydroponic units; plastic beakers filled with $250 \mathrm{~mL}$ of appropriate cadmium concentrations along with their control. An equal quantity of polystyrene beads $(0.5-1.0 \mathrm{~cm}$ diameter) was added to each beaker. Six seedlings of uniform size (7 days old) were transferred to each beaker from the Petri dishes. The experiment was set out in a Complete Randomized design in a glasshouse (thermostatically controlled at $22{ }^{\circ} \mathrm{C}$ ) under natural light conditions. All beakers were aerated during the course of seedling growth and replenished with fresh solutions after 6 days. The $\mathrm{pH}$ of the solutions was maintained at 5.5-6.0 by the addition of $\mathrm{NaOH}$. Seedlings were allowed to grow for 28 days.

\subsection{Fresh and dry biomass measurements}

Seedlings were taken out from the solutions after 28 days and washed with deionized water. Fresh biomass was determined for the seedlings from each beaker. Then plant material was oven dried at $80{ }^{\circ} \mathrm{C}$ for $48 \mathrm{~h}$ and dry weight measurements were taken.

\subsection{Photosynthetic area measurements}

Prior to drying of seedling material, visible necrotic and chlorotic lesions were marked and removed carefully using a sharp scalpel. Fully green portions of the leaves of cadmium treated plants were used for area measurements. All compound leaves samples from each treatment were scanned and the images produced were analysed using Delta-T Scan software.

\subsection{Chlorophyll determination}

Chlorophyll was extracted in $80 \%$ acetone from each treatment unit and chlorophyll a, b and total was quantified spectrophotometrically (U-2000, Hitachi Instrument, Tokyo, Japan) following Arnon (1949).

\subsection{Determination of cadmium content}

Cadmium content in the roots and leaves were determined by digesting $1 \mathrm{~g}$ of oven dried plant material with a solution of $3: 1 \mathrm{HNO}_{3}: \mathrm{HClO}_{4}(\mathrm{v} / \mathrm{v})$. Metal accumulation in plant parts (roots and leaves) was measured by atomic absorption spectrometry (Varian AAS, 1475, California, USA). Samples were analyzed by injecting into a carbon rod atomizer of the atomic absorption spectrophotometer. The cadmium detectability was $0.1 \mathrm{mg} / \mathrm{Kg}$. The recovery rate of the method ranged from $96-98 \%$, with variability index $3.5-10 \%$. The accuracy of the analytical method was confirmed by the determination of the content by AA cadmium standard (Camlab, UK).

\subsection{MDA and proline estimation}

The level of lipid peroxidation, expressed as MDA content, was determined as 2-thiobarbituric acid (TBA) reactive metabolites, according to Heath and Packer (1968). The amount of MDA was calculated using an extinction coefficient $155 \mathrm{mM}^{-1} \mathrm{~cm}^{-1}$ and expressed in $\mu \mathrm{mol} \mathrm{g}{ }^{-1}$ fresh weight. Proline levels were estimated as described by Alia and Saradhi (1991) and expressed in $\mu \mathrm{g} \mathrm{g}^{-1}$ fresh weight.

\subsection{Statistical analysis}

The data were analyzed statistically by one way analysis of variance (ANOVA) using MS EXCEL and Duncan's Multiple Range Test was used to show significant differences between treatments.

\section{Results and Discussion}

Higher concentrations of cadmium had affected seedling growth and a significant reduction $(p \leq 0.05)$ of fresh and dry weights was observed (Figure 1). The seedlings had the maximum fresh weight (6.04 g) under the control. Although, a gradual reduction of fresh biomass was observed at all concentrations of cadmium but the seedlings had the lowest biomass 
$(2.91 \mathrm{~g})$ at $120 \mu \mathrm{m}$ cadmium (Figure 1A). The dry weight also exhibited a similar trend as shown by fresh weight and a noticeable inhibition in dry weight was observed at the most elevated level $(120 \mu \mathrm{M})$ where seedlings produced $1.54 \mathrm{~g}$ of dry weight as compared with $3.37 \mathrm{~g}$ of the control and exhibited a significant $(p \leq 0.05)$ contrast. This extent of decline was 51.01 and $54.30 \%$ for fresh and dry weights, respectively.

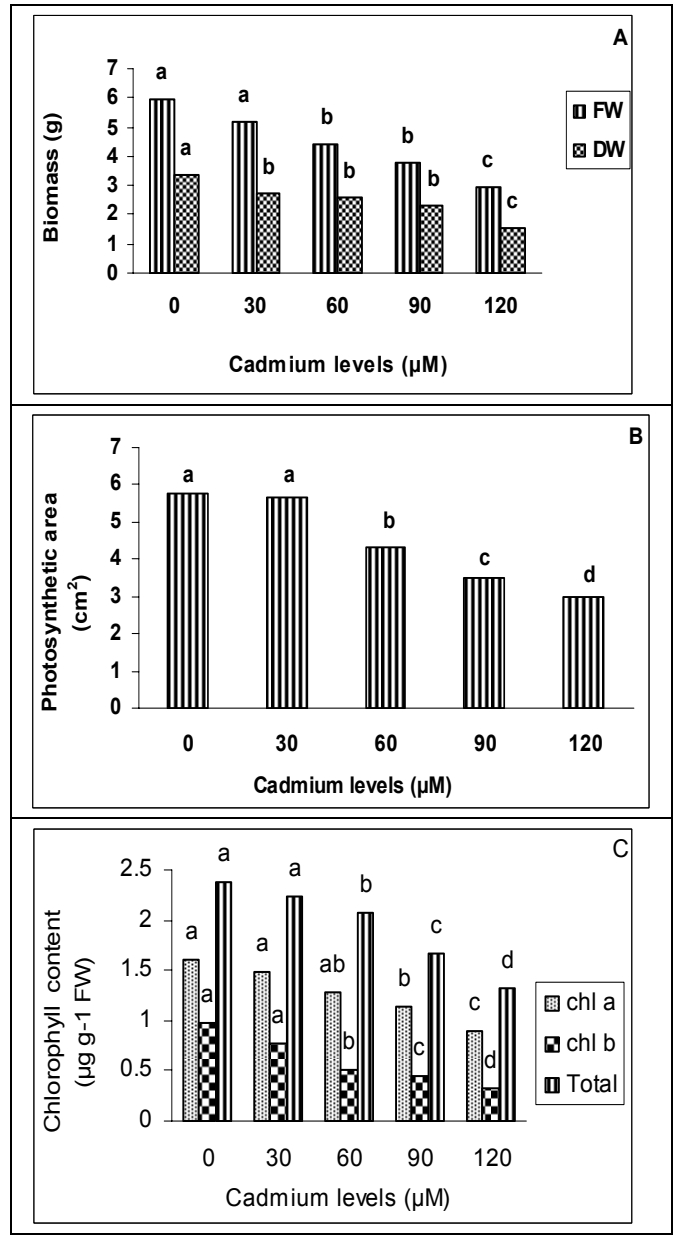

Figure 1. A. Fresh and dry biomass, B. photosynthetic area, C. chlorophyll content of alfalfa seedlings after exposure to various levels of cadmium. Values are means of three replicates. Values designated over the bars sharing same letters are not significantly different at $p<0.05$ level by Duncan's Multiple Range Test.
The growth inhibition in seedlings was accompanied by a significant $(p \leq 0.05)$ decrease in the photosynthetic area (Figure 1B). Seedlings at the control had the maximum photosynthetic area $\left(5.74 \mathrm{~cm}^{2}\right)$. No considerable decline in photosynthetic area was observed at lower levels of cadmium but a profound reduction (47.56 \%) was observed at $120 \mu \mathrm{M}$ where seedlings had shown an area of $3.01 \mathrm{~cm}^{2}$.

Thus, the results for growth parameters clearly demonstrated that excessive cadmium had induced growth inhibition in alfalfa seedlings which is expressed in terms of reduction in fresh and dry biomass of seedlings and photosynthetic area. Jiang et al. (2000) found that cadmium applied to the younger plants of other species caused a stronger reduction in growth parameters such as biomass and leaf area. Peralta-Videa et al. (2004) also reported drastic changes in growth parameters at early growth stages in alfalfa plants after their exposure to this metal. Thus, the sensitivity of seedlings growth in alfalfa is consistent to the findings of these workers.

The chlorophyll contents were comparatively higher under controlled condition but cadmium stress induced a profound decline in chlorophyll a, b and total (Figure 1C). The pigments declined progressively with increasing concentrations of cadmium. The amount of chlorophyll a and b in control was 1.6 and $0.96 \mathrm{mg} \mathrm{g}^{-1}$, respectively. However, after treatment with the highest concentrations of cadmium $(120 \mu \mathrm{M})$, chlorophyll a decreased to $0.89 \mathrm{mg} \mathrm{g}^{-1}$. A dramatic decline in chlorophyll $\mathrm{b}$ content was also observed and $0.32 \mathrm{mg} \mathrm{g}^{-1}$ of this pigment was recorded at the most elevated level of cadmium. At $120 \mu \mathrm{M}$ cadmium, both chlorophyll $\mathrm{a}$ and $\mathrm{b}$ had exhibited a significant $(p \leq 0.05)$ contrast from all other concentrations of cadmium (Figure 1C). The highest concentration caused a decrease by $44.37 \%$ for chlorophyll a but reduction in chlorophyll $\mathrm{b}$ was significantly more drastic (52.94\%) as compared with control. The decline in chlorophyll content in plants is well reported in different groups of plants (Perreault et al. 2011; Sanita di Toppi and Gabbrielli, 1999). The decrease in green pigment content in plants after 
exposure to excessive cadmium can be attributed to reduction in chlorophyll biosynthesis due to inhibition of important enzymes ( $\delta$ aminolevulinic acid dehydratase and protochlorophyllide reductase) associated with the synthesis of green pigments. Similarly, cadmium is believed to induce impairment in the supply of $\mathrm{Mg}$ and Fe which are required for the synthesis of chlorophylls. Moreover, replacement of $\mathrm{Mg}$ ions in tetra pyrole ring of the chlorophyll molecule also bring about reduction in chlorophyll content (Kupper et al. 1996).

The accumulation of cadmium in both plant tissues was concentration dependent (Figure 2A). When plants were grown at higher concentrations $(90$ and $120 \mu \mathrm{M})$ the metal content increased dramatically in the roots and leaves and exhibited a significant $(p \leq 0.05)$ dissimilarity. More cadmium accumulated in the roots and showed a marked increase from $110 \mu \mathrm{g} \mathrm{g}^{-1}$ at $30 \mu \mathrm{M}$ to $1028 \mu \mathrm{g}$ $\mathrm{g}^{-1}$ at $120 \mu \mathrm{M}$. Whereas, cadmium content of the leaves were 188 and $558 \mu \mathrm{g} \mathrm{g}^{-1}$ at 30 and $120 \mu \mathrm{M}$, respectively. Though, tissues of alfalfa accumulated cadmium in their both tissues but the results clearly indicated greater accumulation of cadmium in the roots and a restricted transport to the leaves. The hyper accumulation of cadmium in the roots seems to be allowed by the production of phytochelatins/organic compounds which combined with metal and build non toxic complexes (Bao et al. 2011; Hall, 2002). Additionally, transport and bioaccumulation of metal in the foliage could be influenced by several other factors such as transport mechanism, ionic strength, light, temperature and anoxic conditions (John et al. 2009; Kato et al. 2010).

Cadmium induced an increase in lipid peroxidation level as estimated through MDA production in plant tissues (Figure 2B). An increase in MDA concentration was observed in both tissues at various levels of cadmium. The level of lipid peroxidation was significantly $(p \leq 0.05)$ lower $\left(3.3 \mu \mathrm{mol} \mathrm{g}^{-1}\right)$ at the control but the maximum increase $\left(6.2 \mu \mathrm{mol} \mathrm{g}^{-1}\right)$ in MDA was observed at $90 \mu \mathrm{M}$ in the roots. An increase in MDA content was also observed in the leaves where the amount of MDA was $2.90 \mu \mathrm{mol} \mathrm{g}^{-1}$ at the control but a noticeable increase $\left(5.6 \mu \mathrm{mol} \mathrm{g}^{-1}\right)$ was recorded at $120 \mu \mathrm{M}$.

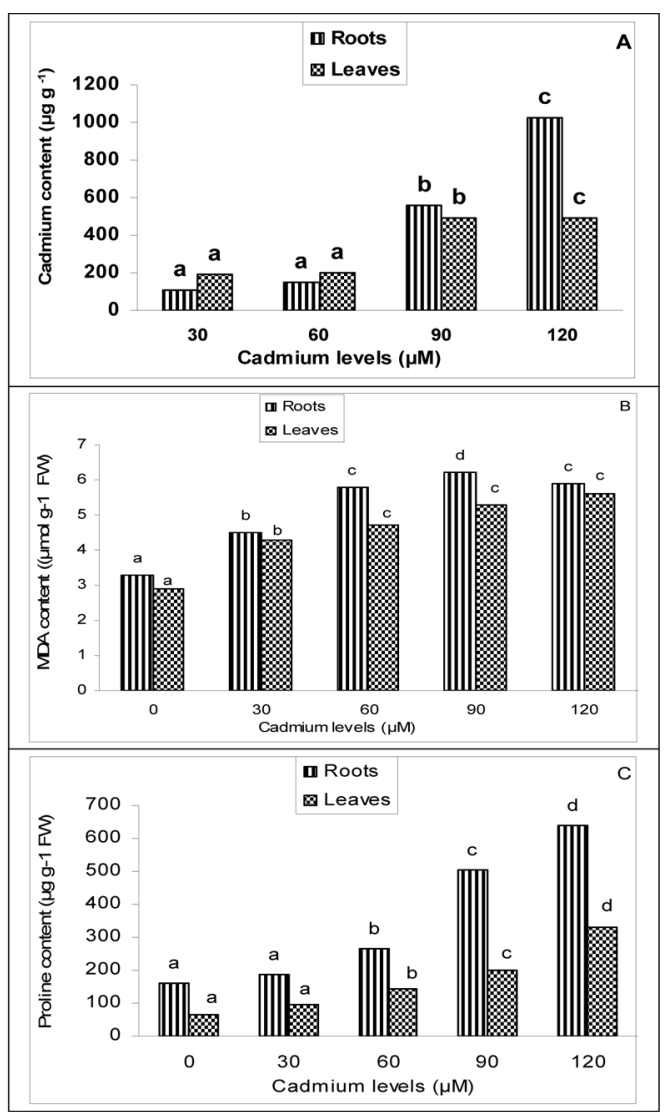

Figure 2. Cadmium content, B. Malondialdehyde C. Proline, in tissues of alfalfa seedlings after exposure to various levels of cadmium. Values are means of three replicates. Values designated over the bars sharing same letters are not significantly different at $p<0.05$ level by Duncan's Multiple Range Test.

Although, lipid peroxidation increased (3.2 to $5.7 \mathrm{mmol}$ $\mathrm{g}^{-1}$ ) at all concentrations of cadmium but significant ( $p \leq$ 0.05 ) increase was observed at $90 \mu \mathrm{M}$ of cadmium in the roots. A greater production of MDA is an indicative of oxidative stress, molecules of biomembranes being important targets attacked by heavy metals ions. An enhanced level of lipid peroxidation (high MDA production) with increasing concentrations of cadmium can be an expression of heavy metal toxicity 
due to the generation of alkoxy and peroxy radicals, which lead to oxidative damage to biological membranes through degradation of polyunsaturated fatty acids. Dhir et al. 2004 has also demonstrated a linear increase in MDA concentrations with increasing cadmium levels in the growth medium. Thus increase in lipid peroxidation signify oxidative stress and is an import manifestation of cadmium toxicity.

The production of proline was significantly $(p \leq 0.05)$ lower, 150 and $180 \mu \mathrm{g} \mathrm{g}^{-1}$ in plants grown at control and $30 \mu \mathrm{M}$ cadmium, respectively. A drastic rise in proline content upto $600 \mu \mathrm{g} \mathrm{g}^{-1}$ in the roots and $320 \mu \mathrm{g} \mathrm{g}^{-1}$ in the leaves was recorded at concentrations greater than $60 \mu \mathrm{M}$ (Figure 2C). Accumulation of proline almost doubled in the roots as compared with the leaves after exposure to cadmium. Proline content at 90 and 120 $\mu \mathrm{M}$ differed markedly $(p \leq 0.05)$ and from all other levels of cadmium in both tissues.

Proline is an amino acid and a compatible solute, its production is well reported in a variety of organisms after their exposure to toxic levels of heavy metals (Giannakoula et al. 2008). The results of this study also indicated an enhanced accumulation of proline with increasing levels of cadmium. Several workers have demonstrated the role of proline in detoxification of free radicals in the presence of heavy metals ions, thus praline accumulation can scavenge oxidative stress. The results of this study clearly demonstrated that cadmium induced enhancement in proline production in the tissues of alfalfa plants which is an indicative of a defensive mechanism against oxidative damage. Proline production is an evolutionary response to stress and had widely been observed in diverse groups of organisms (Chen et al. 2001; Wu et al. 1995).

\section{Conclusions}

The observed changes in the investigated parameters clearly suggested that elevated levels of cadmium had affected growth and chlorophyll production in alfalfa seedlings. Moreover, the enhanced production of MDA indicated oxidative damage as a result of cadmium toxicity. However, the species has shown the ability to sequester metal in the roots and restricted transfer of cadmium ions to the aerial tissue. Additionally, the production of proline appeared to play a key role in defense against cadmium toxicity. Since, the species has shown a threshold for cadmium which seems to acquire by differential accumulation of metals in plant tissues, decreased level of lipid peroxidation after enhancement in proline production at higher concentrations of cadmium. Therefore, alfalfa can be a choice in situations where irrigation water contains appreciable amount of cadmium as well as for the utilization of abandoned soils contaminated with this metal.

\section{Acknowledgement}

The authors are thankful to Pakistan Higher Education Commission, Islamabad for financial assistance (Grant PDF II) and Dr. Azra Meadows, Division of Environmental and Evolutionary Biology, University of Glasgow, UK for her valuable suggestions in the preparation of manuscript.

\section{References}

Alia, A., Saradhi, P.P. 1991. Proline accumulation under heavy metal stress. J. Plant Physiol. 138, 554-558.

Andresen, E., Kupper, H. 2013. Cadmium toxicity in plants. In: Sigel, A., Sigel, H., Sigel, K.O. (eds.). Cadmium: From Toxicity to Essentiality. Metal Science in Life Sciences, 11. Springer, New York, pp. 395-229-414.

Arnon, D.I. 1949. Copper enzymes in isolated chloroplasts: Polyphenoloxidases in Beta vulgaris. Plant Physiol. 24, 1-15. 
Bao, T., Sun, T., Sun, L. 2011. Low molecular weight organic acids in root exudates and cadmium accumulation in cadmium hyperaccumulator Solanum nigrum L.and non- hyperaccumulator Solanum lycopersicum L. Afr. J. Biotechnol.

Basak, M., Sharma, M., Chakraborty, U. 2001. Biochemical responses of Camellia sinensis (L.) O. Kuntze to heavy metal stress. J. Environ. Biol. 22, 37-41.

Chen, C.T., Chen, L.M., Lin, C.C., Kao, C.H. 2001. Regulation of proline accumulation in detached rice leaves exposed to excess copper in plants. Plant Sci. 160, 283-290.

Chmielowska-Bak, J., Izbianska, K., Deckert, J. 2013. The toxic Doppelganger: On the ionic and molecular mimicry of cadmium. Acta Biochem. Polon. 60, 369-374.

Dhir, B., Sharmila, P., Saradhi, P. 2004. Hydrophytes lack potential to exhibit cadmium stress induced enhancement in lipid peroxidation and accumulation of proline. Aquat. Toxicol. 66, 141147.

Elobeid, M., Gobel, C., Feussner, I., Polle, A. 2012. Cadmium interferes with auxin physiology and lignifications in poplar. J. Exp. Bot. 63, 14131421.

Garg, N., Bhandari, P. 2013. Cadmium toxicity in crop plants and its alleviation by arbuscular mycorrhizal (AM) fungi: An overview. Plant Biosyst. DOI.org/ 10.1080/11263504.2013.788096.

Giannakoula, A., Moustakas, M., Mylona, P., Papadakis, L. Yupsanis, T. 2008. Aluminum tolerance in maize is correlated with increased levels of mineral nutrients, carbohydrates and proline, and decreased levels of lipid peroxidation and $\mathrm{Al}$ accumulation. J. Plant Physiol. 165, 385-396.

Hall, J.L. 2002. Cellular mechanism for heavy metals detoxification and tolerance. J. Exp. Bot. 53, 1-11.

Heath, R.L., Packer, L. 1968. Photoperoxidation in isolated chloroplasts. Arch. Biochem. Biophys. 125, 189-198.

Hoagland, D.R., Arnon, D.I. 1950. The water culture method for growing plants without soil. Calif Agric Exp Station, pp. 347-353.

Jiang, W., Liu, D., Hou, W. 2000. Hyper-accumulation of cadmium by roots, bulbs and shoots of garlic (Allium sativum L.). Biores. Technol. 76, 9-13.

John, R., Ahmad, P., Gadgil, K., Sharma, S. 2009. Cadmium and lead-induced changes in lipid peroxidation, antioxidative enzymes and metal accumulation in Brassica juncea L. at three different growth stages. Arch. Agron. Soil Sci. 55, 395-405.

Kato, M., Ishikawa, S., Inagaki, K., Chiba, K., Hayashi, H., Yanagisawa, S., Yoneyama, T. 2010. Posible chemical forms of cadmium and varietal differences in ploem sap of rice plants (Oryza sativa L.). Soil Sci. Plant Nutr. 56, 839-847.

Khan, M.F., Anderson, D.M., Nutkani, M.I., Butt, N.M. 1999. Preliminary results from reseeding degraded Dera Ghazi Khan rangeland to improve small ruminant production in Pakistan. Small Ruminant Res. 32, 43-49.

Kupper, H., Kupper, F., Spiller, M. 1996. Environmental relevance of heavy metal substituted chlorophylls using example of water plants. J. Exp. Bot. 47, 259-266.

Lopez-Millan, A.F., Sagardoy, R., Solanas, M., Abadia, A., Abadia, J. 2009. Cadmium toxicity in tomato (Lycopersicon esculentum) plants grown in hydroponics. Environ. Exp. Bot. 65, 376-385.

Markert, B., Breure, A.M., Zechmeister, H.G. 2003. Bioindicators and Biomoniters-Principles, 
Concepts and Apllications. Elsevier, Amsterdam.

Nriagu, J.O. 1996. A history of global metal pollution. Science. 272, 223-230.

Parmer, P., Kumari, N., Sharma, V. 2013. Structural and functional alterations in photosynthetic apparatus of plants under cadmium stress". Bot. Studies. 54, 45-50.

Peralta-Videa, J.R., De la Rosa, G., Gonzalez, J.H., Gardea-Torresdey, J.L. 2004. Effect of growth stages on the heavy metal tolerance of alfalfa plants. Adv. Environ. Res. 8, 679-685.

Perreault, F., Dionne, J., Didur, O., Juneau, P., Popovic, R. 2011. Effect of cadmium on photosystem II activity in Chlamydomonas reinhardtii alteration of OJIP fluorescence transients indicating the change of apparent activation energies within photosystem II. Photosynth. Res. 107, 151-157.

Raskin, I., Kumar, P.B.A.N., Dushenkov, S., Salt, D.E. 1994. Bioconcentration of heavy metals by plants. Curr. Opin. Biotech. 5, 285-290.

Reeves, R.D., Baker, A.J.M. 2000. Metalaccumulating plants, In: Raskin, I, Ensley, B. D. (eds.). Phytoremediation Toxic Metals: Using Plants Clean Up Environment. John Wiley and Sons, New York. pp. 193-229.
Reeves, R.D., Baker, A.J.M. 2000. Metalaccumulating plants, In: Raskin, I, Ensley, B. D. (eds.). Phytoremediation Toxic Metals: Using Plants Clean Up Environment. John Wiley and Sons, New York. pp. 193-229.

Sandalio, L.M., Dalurzo, H.C., Gomez, M., RomeroPuertas, M.C., Delrio, L.A. 2001. Cadmium-induced changes in the growth and oxidative metabolism of pea plants. J. Exp. Bot. 52, 2115-2126.

Sanita di Toppi, L., Gabbrielli, R. 1999. Responses to cadmium in higher plants. Environ. Exp. Bot. 41, 105-130.

Sharma, S., Sharma, P., Melhotra, P. 2010. Bioaccumulation of heavy metals in Pisum sativum L. growing in fly ash amended soil. J. Amer. Sci. 6, 43-50.

Sigel, A., Sigel, H., Sigel, K.O. 2013. Cadmium: From Toxicity to Essentiality. Metal Science in Life Sciences, 11. Springer, New York.

Vasslive, A. 2002. Physiological and agro-ecological aspects of cadmium interactions with barley plants: an overview. J. Cent. Eur. Agric. 4, 65-74.

Wu, J.T., Chang, S.J., Chou, T.L. 1995. Intracellular proline accumulation in some algae exposed to copper and cadmium. Bot. Bull. Acad. Sinica. 36, 89-93. 